\title{
O CURSO DE PEDAGOGIA DA UFAC: 50 ANOS DE ENFRENTAMENTO E RESISTÊNCIA NA DEFESA DA FORMAÇÃO DE PROFESSORES
}

\author{
Ufac's pedagogy course: 50 years of confrontation and resistance in defense of teacher training \\ La carrera de Pedagogía de Ufac: 50 años de enfrentamiento y resistencia en la defensa de la \\ formación de profesores \\ Adriana Ramos dos Santos* \\ Mark Clark Assen de Carvalho** \\ Tatiane Castro dos Santos***
}

\section{Resumo}

O presente estudo tem como objetivo apresentar uma reflexão sobre o desenvolvimento do curso de Pedagogia da Universidade Federal do Acre, como forma de destacar sua trajetória e o movimento que vem sendo realizado desde os idos da década de 1980 para assumir e resguardar a formação dos professores dos Anos Iniciais do Ensino Fundamental como seara própria dessa área de formação, com relevo, também, para as contribuições e legados do curso no movimento de ampliação do nível de formação dos professores na realidade acreana. Em perspectiva, busca, ainda, discutir as feições que o projeto pedagógico curricular do curso assumiu a partir das orientações constantes da Resolução CNE/CP, n 1/2006, da Resolução 02/2015 e as implicações decorrentes da aprovação da Resolução 02/2019 do CNE, a qual caminha na contramão das questões historicamente defendidas pelo movimento nacional. Trata-se, portanto, de uma pesquisa bibliográfica e documental de abordagem qualitativa, construída através de revisão bibliográfica e análise de documentos. Para a construção do aporte teórico, a pesquisa apoia-se em autores como: Aguiar e Dourado (2019); Bazzo e Scheibe (2019); e em publicações de entidades educacionais como a Anfope e a ANPEd. O estudo contribui para evidenciar alguns enfrentamentos e resistências em contexto local articulado às questões que, nacionalmente, têm pautado o debate no curso de Pedagogia em tempos que afloram o desmonte das políticas e controvérsias que parecem 
desconsiderar o processo de construção coletiva empreendido pelo movimento nacional, a autonomia das instituições de formação e a definição de um projeto institucional de formação de professores.

Palavras-chave: Curso de Pedagogia; Diretrizes Curriculares Nacionais; Formação de Professores; Ufac.

\begin{abstract}
The present study aims to present a reflection on the development of Federal University of Acre's Pedagogy Course, as a way to highlight its trajectory and the movement that and the movement that has been taking place since the 1980s in order to assume and safeguard the training of teachers for early years of elementary school as a specific field of this training area, with emphasis, also on the contributions and legacies of this course in the movement to increase the level of teacher training in Acre's reality. In perspective, it also seeks to discuss the features that the course's pedagogical project assumes from Resolution CNE/CP, n. 1/2006 guidelines, from Resolution 02/2015 of CNE and the implications arising from the approval of Resolution 02/2019 of CNE, which tread opposing directions of issues historically defended by the national movement. It is, therefore, a bibliographic and documentary research with a qualitative approach, built through bibliographic review and analysis of documents. To build the theoretical input, this research is supported by authors such as: Aguiar and Dourado (2019); Bazzo and Scheibe (2019); and in publications by educational entities such as Anfope and ANPEd. The study contributes to reveal some confrontations and resistance in a local context articulated with issues that, nationally, have guided the debate in the Pedagogy Course in times that blooms the dismantling of policies and controversies that seem to disregard the collective construction process undertaken by the national movement, the autonomy of teacher training institutions and the definition of an institutional teacher training project.
\end{abstract}

Keywords: Pedagogy Course; National Curriculum Guidelines; Teacher training; Ufac.

\title{
Resumen
}

El presente estudio tiene como objetivo presentar una reflexión sobre el desarrollo de la Carrera de Pedagogía de la Universidad Federal de Acre, como forma de evidenciar la trayectoria de esa carrera y el movimiento de enfrentamiento y resistencia realizado para resguardar la formación de los profesores de los años iniciales de la enseñanza fundamental como campo fértil propio de esa área de formación, con relieve, también, para las contribuciones y legados de la carrera en el movimiento de ampliación del nivel de formación de los profesores acreanos. En perspectiva, busca, igualmente, discutir los rasgos del proyecto pedagógico curricular de la carrera con las orientaciones de la Resolución CNE/CP, $n^{\circ} 1 / 2006$, de la Resolución 02/2015 del CNE e implicaciones de la Resolución 02/2019 del 
CNE, que avanzan en el sentido contrario de las cuestiones históricamente defendidas por el movimiento nacional. Se trata, por lo tanto, de una investigación de tipo bibliográfica y documental orientada en una perspectiva cualitativa, construida a través de la revisión bibliográfica y análisis documental. Para la construcción del aporte teórico, la investigación se apoya en autores como: Aguiar y Dourado (2019); Bazzo y Scheibe (2019); y en publicaciones de entidades educacionales como la Anfope y la ANPEd. El estudio pone en evidencia los enfrentamientos y resistencias en el contexto local articulado con cuestiones que, nacionalmente, han pautado el debate en la Carrera de Pedagogía en tiempos que afloran el desmonte de las políticas y controversias que parecen desconsiderar el proceso de construcción colectiva emprendido por el movimiento nacional, la autonomía de las agencias de formación y la definición de un proyecto institucional de formación de profesores.

Palabras clave: Carrera de Pedagogía; Directrices Curriculares Nacionales; Formación de Profesores; Ufac.

\section{Introdução}

O presente estudo traz uma reflexão acerca do curso de Pedagogia e de seu reordenamento, pretendido pelas atuais Diretrizes Nacionais para a Formação Inicial de Professores da Educação Básica e Base Nacional Comum para a Formação Inicial, instituídas pela Resolução n.02/2019. Para empreender uma discussão sobre o referido curso, é preciso considerar os enfrentamentos, as resistências e as tensões que perpassam todos os momentos de sua história e que envolvem questões que vão desde o seu perfil, passando por sua identidade, até o seu reconhecimento como licenciatura.

Para tanto, a discussão aqui proposta inicia-se com a demarcação de alguns elementos que, do ponto de vista histórico, refletem o processo de criação do curso de Pedagogia no estado do Acre nos idos da década de 1970, articulado, em âmbito nacional, com as orientações do Parecer 252/69 do Conselheiro Valnir Chagas. Posteriormente, detém-se aos debates que marcaram o movimento nacional nas décadas subsequentes, até o momento em que foram aprovadas as Diretrizes Curriculares Nacionais para o curso de Pedagogia, passando pela aprovação das Diretrizes Curriculares Nacionais para Formação Inicial e Continuada dos Profissionais do Magistério, a Resolução 02/2015, posteriormente reformulada pela Resolução 02/2019. São destacados, também, outros atos normativos formulados ao arrepio das instituições e entidades diretamente ligadas ao campo da formação de professores. 
Diante desse contexto, o estudo tem como objetivo apresentar uma reflexão sobre o percurso histórico de desenvolvimento do curso de Pedagogia da Ufac, algumas das tensões e resistências que margeiam sua história, a considerar que, de seus 50 anos de existência, 30 são dedicados exclusivamente à formação de professores, em tempos em que se acusava o curso de não possuir identidade em termos de definição de um perfil de profissional a ser formado. Na esteira da discussão aqui proposta, são inseridas algumas das implicações e consequências que decorrerão da possível implantação das novas Diretrizes Curriculares Nacionais para a Formação de Professores (Resolução CNE/CP n. 02/2019).

Trata-se, portanto, de uma pesquisa bibliográfica e documental de abordagem qualitativa, construída através de revisão bibliográfica e análise de documentos, resoluções e pareceres legais, além de referências ao Projeto Pedagógico Curricular do curso de Pedagogia da Universidade Federal do Acre

Cabe salientar que esse movimento de historicização das políticas curriculares em nível nacional tem sido acompanhado e questionado atentamente por diversos pesquisadores; a temática da formação de professores e as questões a ela relacionadas mobilizam uma série de pesquisas sob diferentes ângulos. Muitas análises estão sendo realizadas acerca da formação e da complexa relação que se estabelece na elaboração de políticas curriculares e nos seus efeitos sobre a formação docente. Nesse debate, destacam-se os trabalhos de Leda Scheibe (2019), Vera Maria Candau (2013), Alice Casimiro Lopes (2018), Elisabeth Macedo (2016), dentre outros.

Quando se fala em políticas curriculares, é necessário ressaltar que o currículo é um território de disputas; pode-se entendê-lo tanto como um campo de toda sorte de estratagemas, interesses e relações de dominação e controle social, quanto como parte do processo de regulação social, que busca organizar as formas de pensar, de agir e de sentir dos sujeitos. Nesse sentido, não se pode ignorar que se trata de uma produção imersa em relações de poder, estabelecidas em diversas esferas e níveis, tanto em um aspecto macrossocial, quanto em um aspecto micro, interno à instituição e aos sujeitos que a compõem, tanto em nível vertical, quanto horizontal (GOODSON, 1995, 1997; POPKEWITZ, 1997). Os processos de (re)formulação dos currículos dos cursos de formação de professores, neste caso específico, do curso de Pedagogia, expressam essas relações.

Desse modo, as questões abordadas neste artigo contribuem para ampliar ainda mais esse debate e apresentam uma maior relevância devido ao momento político que se vive no país. Ao mesmo tempo em que se busca, aqui, reconstruir a trajetória do curso de 
O curso de Pedagogia da UFAC: 50 anos de enfrentamento e resistência na defesa da formação de professores

Pedagogia de uma instituição (a Ufac), discute-se um movimento de reformas, avanços e retrocessos no campo da formação de professores com impactos em nível nacional.

\section{A trajetória do curso de Pedagogia no Brasil e na UFAC}

O processo de inserção do curso de Pedagogia no contexto universitário ocorreu em 1939, no âmbito da Faculdade Nacional de Filosofia da Universidade do Brasil, através do Decreto-lei n. ${ }^{\circ} 1.190$, de 4 de abril de 1939. Com o intuito de formar bacharéis e licenciados, o curso apresentava-se no modelo $3+1$, no qual os três primeiros anos eram voltados para a formação do bacharel com conhecimentos metodológicos e cognitivos e o último ano estava direcionado para a formação do licenciado, realizada no curso de Didática (BRASIL, 1939).

O curso de Pedagogia permaneceu, até os anos 60, com esse mesmo formato e só modificou essa lógica de formação com a promulgação da primeira Lei de Diretrizes e Bases, $n^{\circ} 4.024 / 61$, que lhe trouxe uma nova configuração. No que se refere ao currículo, o Parecer no 251/62 (BRASIL, 1963) regulamentou o currículo mínimo, contendo as disciplinas do bacharelado: Psicologia da Educação, Sociologia (geral e também da Educação), História da Educação, Filosofia da Educação, Administração Escolar e outras duas disciplinas presentes em uma lista no Parecer, podendo essas serem escolhidas pela própria instituição que ofertava o curso (BRASIL, 1963).

A Reforma Universitária de 1968 (Lei 5.540/68) atingiu, sobretudo, o cerne do modelo de universidade e passou a dar sustentação ao formato que predomina até os dias atuais. Dentre essas mudanças, destacam-se: a indissociabilidade entre pesquisa, ensino e extensão, a definição dos departamentos como menor fração da estrutura universitária, o vestibular classificatório, a organização das instituições de ensino superior, podendo ser de ordem pública ou privada e a configuração do currículo do curso de Pedagogia em habilitações (Administração, Supervisão, Orientação e Inspeção Escolar), com base no Parecer n ${ }^{\circ}$ 252/69 (BRASIL,1969). Ao promover a reestruturação do ensino superior, a Reforma Universitária substituiu as antigas Faculdades de Filosofia, Ciências e Letras pelas Faculdades de Educação, sendo estas responsáveis pela oferta do curso de Pedagogia e pela formação pedagógica nos demais cursos de licenciatura.

No bojo das mudanças operadas a partir da década de 1960 e seguindo o modelo da racionalidade técnica, que ganhou forma na Lei 5.540/68, a qual institui a Reforma Universitária (BRASIL, 1968), o Parecer no 252/69, de autoria do Conselheiro Valnir Chagas, estabeleceu para as Faculdades de Educação a oferta de disciplinas pedagógicas 
para as licenciaturas e a formação do pedagogo, com habilitações técnicas em: Supervisão Escolar; Administração Escolar, Orientação Educacional e Inspeção Escolar, em cujas ênfases e orientações ficavam subsumidas as especificidades da formação de professores.

Na década de 1970, o MEC abriu debate em nível nacional sobre a reformulação dos cursos de formação do educador, incluindo-se o curso de Pedagogia, retomando a discussão sobre a especificidade e a identidade do curso e reavivando a polêmica sobre os especialistas/generalistas e professores/ especialistas na formação do pedagogo.

Assim, a partir da década de 1980, começaram a ocorrer reformulações dos cursos de Pedagogia no Brasil, fortemente influenciadas pelo amplo debate nacional sobre a formação dos profissionais da educação, que redundou na criação da Associação Nacional pela Formação dos Profissionais da Educação (Anfope), de modo que a questão da formação dos professores passou a figurar nos debates com maior frequência, contribuindo, também, com a ampliação de estudos e pesquisas no campo da formação docente.

Com a promulgação da atual Lei de Diretrizes e Bases da Educação Nacional (Lei $n^{\circ}$ 9.394/96), foi revogada grande parte da legislação referente à formação de professores existentes até então no país, sendo formuladas novas disposições que foram desde as tentativas de criação dos Institutos Superiores de Educação, passando pela "infeliz" ideia de criação dos Cursos Normais Superiores, os quais, em tese, passariam a responder pela formação dos professores para atuar nos Anos Iniciais do Ensino Fundamental. Isso representou, na ocasião, uma flagrante tentativa de esvaziamento do curso de Pedagogia e mais um prenúncio de se retirar dele a formação de professores para os anos iniciais da escolaridade obrigatória.

Dentro dessas circunstâncias, foram editados decretos, resoluções, diretrizes curriculares e outras iniciativas de reformas no campo da educação que impactaram os cursos de licenciatura. Sobre essa questão, importa destacar a edição do Decreto $n^{\circ}$ 3.276/ 1999, que dispõe que a formação dos professores para atuar nas séries iniciais do Ensino Fundamental e na Educação Infantil seria ofertada exclusivamente nos Cursos Normais Superiores e não mais nos espaços universitários dos cursos de Pedagogia. Sendo assim, esse novo formato da formação dos professores ensejada pelo decreto pretendia deslegitimar algumas experiências formativas nos cursos de Pedagogia, retirando deles a tarefa de formar professores da Educação Infantil e Anos Iniciais do Ensino Fundamental.

No intuito de possibilitar a formação profissional docente distante do modelo universitário de ensino, pesquisa e extensão, a LDB pretendeu regularizar os Institutos Superiores de Educação, a fim de ofertar, nesses espaços, o Curso Normal Superior. O Instituto Superior de Educação e o Curso Normal Superior, destinados à formação dos 
docentes, tornaram-se alternativas para a formação de profissionais da educação para administração, planejamento, supervisão e orientação educacional para a educação básica (graduação em Pedagogia ou em nível de pós-graduação). Tal determinação gerou forte reação dos movimentos de educadores no Brasil.

Foi nesse contexto que houve a edição do Decreto 3.554, de 7/8/2000, que alterou a redação do parágrafo $2^{\circ}$ do Art.13 do Decreto 3.276, de 6/12/99, para substituir a palavra "obrigatoriamente" por "preferencialmente", a fim de permitir que os cursos de Pedagogia continuassem a habilitar professores para o magistério da Educação Infantil e dos Anos Iniciais do Ensino Fundamental, pois, pela redação original dada ao Decreto 3.276, somente os Cursos Normais Superiores poderiam ofertar esse tipo de formação.

No movimento de formulação e implantação de diretrizes para os cursos de formação de professores, as do curso de Pedagogia só viriam a ser aprovadas anos mais tarde, mediante a aprovação da Resolução CNE/CP $n^{\circ} 1 / 2006$, que estabelece as Diretrizes Curriculares Nacionais para o curso de Pedagogia e destaca que as referidas diretrizes

aplicam-se à formação inicial para o exercício da docência na Educação Infantil e nos anos iniciais do Ensino Fundamental, nos cursos de Ensino Médio, na modalidade Normal, e em cursos de Educação Profissional na área de serviços e apoio escolar, bem como em outras áreas nas quais sejam previstos conhecimentos pedagógicos $\left(\operatorname{Art} .2^{\circ}\right)$.

Com as diretrizes específicas, o curso de Pedagogia constitui-se como o principal lócus da formação superior de professores para atuação na Educação Infantil e nos Anos Iniciais do Ensino Fundamental, passando essa formação a constituir, reconhecidamente, um dos requisitos para o desenvolvimento educacional do Brasil.

No estado do Acre, segundo analisa Carvalho (2004), a implantação dos primeiros cursos de licenciatura foi inspirada nas orientações e determinações advindas da Lei 5.540/68, particularmente em seu artigo 30, que determina:

A formação de professores para o ensino de $2^{\circ} \mathrm{Grau}$, de disciplinas gerais e técnicas, bem como o preparo de especialistas destinados ao trabalho de planejamento, supervisão, administração, inspeção e orientação no âmbito de escolas e sistemas, far-se-á em nível superior (Art. 30).

O curso de Pedagogia da Ufac tem sua origem vinculada à criação da Faculdade de Educação e do Centro Universitário do Acre, por meio da Lei estadual no 318, de 03 de março de 1970, sendo autorizado pelo Conselho Estadual de Educação através do Decreto ${ }^{\circ}$ 68567, de 29 de abril de 1971. Nesse mesmo ano, instala-se a Faculdade de 
Educação, que absorveu o referido curso, tendo como objetivo "formar recursos humanos para a área de educação e realizar a formação pedagógica nas Licenciaturas” (UFAC, 1991, p.05).

Em 1975, pelo Parecer CFE no 4009/75 e Decreto Federal n ${ }^{\circ}$ 76851/75, o curso de Pedagogia obteve seu reconhecimento em âmbito federal, com a transformação do Centro Universitário em Fundação Universidade Federal do Acre, através da Lei Federal $\mathrm{n}^{\mathrm{o}}$ 6023/74. Nesse mesmo período, houve uma reestruturação administrativa e organizacional na Ufac, momento em que a antiga Faculdade de Educação se transformou em Departamento de Educação, pela Resolução 71, de 22 de dezembro de 1977, para o qual foi transferido o curso de Pedagogia, tendo seu colegiado de curso instituído pela Resolução Cepex nº 66/79.

No que se refere à organização curricular, o curso de Pedagogia da Universidade Federal do Acre acompanhava as determinações legais emanadas do Parecer CFE $\mathbf{n}^{\mathbf{o}}$ 252/69 e da Resolução CFE 2/69, conforme revelavam os objetivos do curso, os quais consistiam em "habilitar professores para as matérias pedagógicas do segundo grau e habilitar profissionais nas áreas de administração escolar, orientação educacional, inspeção escolar e supervisão escolar"' .

Esses objetivos e a organização curricular do curso passam a ser objeto de sucessivas análises e revisões motivadas por reivindicações sustentadas em uma "sólida fundamentação teórica da qual possa emergir uma consciência crítica e a inclusão de habilitações de magistério nas áreas de pré-escola, educação de adultos, educação popular, educação especial e séries iniciais do ensino de $1^{\circ}$ grau" (UFAC, 1991, p. 12). Esse processo de análise e de reordenamento do curso no interior da Universidade Federal do Acre foi desencadeado a partir de um seminário interno realizado no ano de 1982.

No decorrer dos dez anos seguintes, intensificou-se o movimento próreformulação, liderado pelo colegiado do curso, que promove atividades como semanas de Educação, seminários envolvendo as secretarias de educação estadual e municipal, enquanto agências contratantes, discentes, egressos e docentes do Departamento de Educação. As temáticas que centralizavam os debates nesses eventos apontavam para a necessidade de definição e elaboração clara dos pressupostos político-pedagógicos orientadores do curso e da identidade profissional do pedagogo, bem como das novas habilitações profissionais.

\footnotetext{
${ }^{1}$ Proposta de Reformulação Curricular do Curso de Pedagogia (UFAC, 1991, p. 05).
} 
Do movimento acima relatado, resulta a Proposta de Reformulação do Curso de Pedagogia, que tem sua implantação efetivada no primeiro semestre de 1992. A proposta implantada tem como marca fundamental a desativação das habilitações técnicas e a ênfase na formação do professor, revelada na definição do magistério - das disciplinas de Fundamentos da Educação para o Curso de Formação de Professores em nível de $2^{\circ}$ grau, Magistério para as séries iniciais do primeiro grau e Didáticas para o curso de Magistério de segundo grau - enquanto habilitações obrigatórias.

Na proposta de 1992, transparece a preocupação com uma organização curricular mais flexível, expressa na presença de disciplinas obrigatórias complementares, optativas e eletivas. A preocupação com a relação teoria e prática no processo formativo resultou na presença de uma disciplina integradora - Prática educativa - que tinha a finalidade de "efetivar a inserção dos alunos e professores na realidade nacional, constituindo-se os dados resultantes dessa intervenção o núcleo de reflexão das disciplinas teóricas do semestre" (UFAC, 1991, p. 15).

No transcurso do processo de implantação da proposta formativa, a delegacia do Ministério da Educação do Acre questionou a nomenclatura da habilitação obrigatória do curso de Pedagogia, uma vez que, pela Portaria Ministerial 26/79, a habilitação de professores para atuar em ensino de $2^{\circ}$ grau, curso de Magistério, obrigatoriamente, deveria denominar-se: Magistério das Matérias Pedagógicas do $2^{\circ}$ grau. Considerando esse questionamento, a Universidade Federal do Acre, através da Resolução n. 16/96, alterou a nomenclatura da habilitação do curso de Pedagogia e transformou-a em habilitação única.

Essa modificação trouxe consequências significativas para a formação do pedagogo acreano: altera consubstancialmente as diretrizes formativas iniciais da proposta, posto que extinguiu a habilitação de "Magistério para as séries iniciais do $1^{\circ}$ grau" e, dessa forma, reafirmou a prevalência da ideia da formação do professor das séries iniciais como um subproduto (UFAC, 2009).

Esse amplo debate sobre um novo projeto do curso de Pedagogia foi concluído em 2009, com a apresentação do documento denominado "Projeto Pedagógico do Curso de Licenciatura em Pedagogia", que abrange, além de introdução, bibliografia e anexos, os seguintes itens: procedimentos e estratégias para elaboração da reforma curricular do curso de licenciatura em Pedagogia; justificativa da elaboração da proposta de reforma curricular integral do curso; concepção do curso: pressupostos da formação do pedagogo; objetivos do curso de Pedagogia; estrutura curricular. 
A proposição referencia-se nos seguintes instrumentos legais: Lei de Diretrizes e Bases da Educação Nacional - Lei no 9.394/1996; Parecer do Conselho Nacional de Educação/Conselho Pleno - CNC/CP 05/2005; Resolução do Conselho Nacional de Educação/Conselho Pleno (CNE/CP) N. ${ }^{\circ}$, de 15 de maio de 2006, que institui Diretrizes Curriculares Nacionais para o Curso de Graduação em Pedagogia.

Em linhas gerais, a nova proposição do currículo do curso de Pedagogia da Ufac procura se assentar na produção acadêmica que aponta a prática como uma atividade social e profissional reconhecida, espaço de construção de saberes que enfatiza sua produção com base na prática cotidiana, impulsionada pelas experiências e pelo conhecimento acadêmico. Parte da compreensão de que existe uma pluralidade de saberes, os quais são "resultado de um processo que envolve uma série de saberes originários da formação, da área disciplinar, do currículo, da experiência, da prática social, regida por uma racionalidade apoiada em representações, crenças, valores e elementos contextuais" (LIMA, 2002, p. 05).

A análise das orientações que compõem o Projeto Pedagógico Curricular do Curso de Pedagogia da Ufac indicam que as diretrizes gerais da formação e o desenho do currículo se aportam na racionalidade instrumental, posto que valorizam a prática individual e coletiva como lugar de aprendizagem dos conhecimentos necessários à profissão, contrapondo-se às práticas formativas apoiadas no modelo da racionalidade técnica, que estabelece uma clara "hierarquia entre o conhecimento básico e aplicado e as derivações técnicas da prática profissional” (PÉREZ GÓMEZ, 1992, p.107).

A aprovação, pelo Conselho Nacional de Educação, da Resolução ${ }^{\circ} 02$, de $1^{\circ}$ de julho de 2015, que dispôs sobre novas regulamentações para a formação inicial e formação continuada do magistério da educação básica, demandou da coordenação do curso (2016-2019) o desencadeamento de um novo processo de discussão para a reformulação do Projeto Pedagógico. Esse momento significou uma oportunidade ímpar de reflexão sobre o projeto formativo, não só para responder a uma exigência legal, mas, sobretudo, pelo compromisso de melhorar a qualidade da formação de professores para atuação tanto na Educação Infantil quanto nos Anos Iniciais do Ensino Fundamental.

A responsabilidade de liderar esse processo de discussão coube à Comissão de Reformulação do PPC, que passou a debater os problemas identificados na matriz curricular vigente, à luz das Diretrizes Curriculares Nacionais (DCNs) para a Formação Inicial e Continuada dos profissionais do magistério. Esta pressupõe o alinhamento entre o Projeto Pedagógico Institucional (PPI), o Plano de Desenvolvimento Instituição (PDI), o Plano Estratégico Institucional (PEI) e o Projeto Pedagógico de Curso (PPC) 
(Resolução 2/2015 do CNE), bem como a abordagem das questões que envolvem: Direitos Humanos, Questões Ambientais, Diversidade Étnico-Racial, de Gênero, de Faixa Geracional, dentre outros.

Essas discussões foram grandemente influenciadas pelas orientações constantes na Resolução 2/2015 do CNE, o redimensionamento da distribuição da carga horária do curso, a saber: $400 \mathrm{~h}$ de estágio obrigatório; 400h de prática como componente curricular; 200h de atividade complementar; e 2.200h de disciplinas.

Uma das primeiras questões a serem equacionadas pelo Comissão dizia respeito aos dispositivos da Resolução n. 2/2015, que preveem a organização do currículo em três núcleos estruturadores, bem como a organização por áreas especializadas, componentes curriculares, campos de conhecimento ou interdisciplinar.

Quanto às atividades de extensão, foi efetivado um levantamento das variadas ações extensionistas do Centro de Educação, Letras e Artes (programas, projetos, palestras, oficinas, eventos científicos, dentre outras), verificando-se as suas potencialidades para o desenvolvimento de processos de formação inicial dos graduandos de várias licenciaturas da Ufac.

O diagnóstico mostrou que deveriam ser feitas algumas mudanças institucionais para a oferta de ações extensionistas, a fim de que fosse possível aos estudantes integralizar os $10 \%$ da carga horária do curso destinada às Ações Curriculares de Extensão (ACEx). Com o intuito de dar maior precisão à estrutura curricular, alguns componentes foram assumindo uma nova nomenclatura e outros foram reposicionados, de modo a garantir a coerência com os princípios organizativos do currículo, a flexibilidade curricular, a sequência de estudos e a coerência interna entre os componentes curriculares.

Nesse sentido, foram retiradas da proposta anterior as disciplinas Fundamentos Filosóficos da Educação, Fundamentos Psicológicos da Educação e Fundamentos da História da Educação. O critério de flexibilidade curricular encontra-se evidenciado na retirada do pré-requisito de algumas disciplinas do projeto anterior, pois buscou-se organizar um currículo em que as disciplinas teóricas/práticas sejam independentes, embora organicamente situadas e que contribua com o fluxo dos alunos no processo formativo.

O curso, então, foi pensado considerando os pressupostos teóricos, os debates, os dados dos estudos e do trabalho dos eixos, os aspectos relativos aos contextos locais e aos 
estudantes. Todo esse processo se refletiria em uma Matriz Curricular que privilegiasse a qualidade e a articulação entre pesquisa, teoria e prática, ou seja, em uma matriz curricular mais leve e mais articulada entre os campos de conhecimento que compõem a base da formação, incluindo os de atuação e as exigências das DCN (2015).

Quanto à carga horária, essa mudança desdobra-se em uma distribuição mais equilibrada, preservando todas as áreas de conhecimento presentes na matriz anterior do curso, sem, contudo, destinar carga horária maior a nenhuma delas. Essa decisão permitiu garantir a presença de todas as áreas de conhecimento entendidas como necessárias pelo corpo docente sem que alguma fosse privilegiada.

O prazo estabelecido na Resolução CNE/CP 02/2015 para sua efetiva implantação fora de dois anos após a publicação. Pressupunha-se, daí, que, até julho de 2017, os cursos de licenciatura deveriam ter reformulado seus projetos pedagógicos. Contudo, não foi isso o que aconteceu, resoluções do próprio Conselho Nacional de Educação tomaram a iniciativa de alterar, por duas ocasiões, as datas para a implantação da norma.

O primeiro adiamento concretizou-se por meio da Resolução $\mathrm{CNE} / \mathrm{CP} \mathrm{n}^{\circ} 1$, de 9 de agosto de 2017 (BRASIL, 2017), que alterou o Art. 22 da Resolução CNE/CP nº 2, de julho de 2015, nos seguintes termos:

Art. $1^{\circ}$ Alterar o prazo, previsto no Art. 22, da Resolução CNE/CP ${ }^{\circ}$ 2 , de $1^{\circ}$ de julho de 2015, que passa a ter a seguinte redação: Art. 22. Os cursos de formação de professores, que se encontram em funcionamento, deverão se adaptar a esta Resolução no prazo de 3 (três) anos, a contar da data de sua publicação. Art. $2^{\circ}$ Esta Resolução entrará em vigor na data de sua publicação (BRASIL, 2017).

O segundo adiamento foi respaldado pela Resolução do $\mathrm{CNE} / \mathrm{CP} \mathrm{n}^{\circ} 3$, de outubro de 2018, a qual estabeleceu um prazo de quatro anos, a partir da data da publicação da Resolução CNE/CP n 02/2015, adiando, portanto, para julho de 2019, a imperiosidade de sua implementação. Seguindo essa determinação, a comissão do PPC do curso de Pedagogia da Ufac seguia para a finalização projeto, atendendo aos preceitos dessa Resolução. O passo seguinte seria a discussão e aprovação no colegiado do curso. Porém, a comissão foi surpreendida com a aprovação da Resolução CNE/CP $\mathrm{n}^{\circ} 1$, de 2 de julho de 2019 (BRASIL, 2019), cujo Art. $1^{\text {o }}$ alterou novamente o Art.22 da Resolução. 02, de 2015, quanto ao prazo de sua já lendária implantação, passando, então, a vigorar a seguinte redação:

A Resolução. $\mathrm{CNE} / \mathrm{CP} \mathrm{n}^{\circ} 2$, de $1^{\circ}$ de julho de 2015, passa a vigorar com a seguinte alteração: Art.22 - Os cursos de formação de professores, que se encontram em funcionamento, deverão se adaptar a esta 
Resolução no prazo máximo de 2 (dois) anos, contados da publicação da Base Nacional Comum Curricular, BNCC, instituída pela Resolução $\mathrm{CNE} / \mathrm{CP} \mathrm{n}^{\circ} 2$, de 22 de dezembro de 2017, publicada no Diário Oficial da União (DOU) de 22 de dezembro de 2017 (BRASIL, 2019).

Dessa forma, o curso de Pedagogia da Ufac, que ainda não havia concluído o processo de discussão e efetiva implantação da nova normativa, viu-se diante do dilema de qual caminho tomar nesse desfavorável cenário que o texto da Resolução $\mathrm{CNE} / \mathrm{CP} \mathrm{n}^{\circ}$ 02/2015 defendia e preconizava.

O curso de Pedagogia da Ufac comemorou, no ano de 2020, em meio a essas tensões e disputas, 50 anos de existência e funciona no turno vespertino. A grande maioria dos discentes são mulheres na faixa etária de 20 a 45 anos. Possui uma carga horária de 3.525 horas, com a duração mínima de quatro anos. O curso propõe-se a preparar o profissional para o exercício do magistério na Educação Infantil e Anos Iniciais do Ensino Fundamental. São cinco décadas de intervenção direta na sociedade, contribuindo para consolidar a proposta educativa da Ufac para a população acreana.

Conforme preconizado pelo estatuto da instituição, a Ufac tem como finalidades a produção e a difusão de conhecimento, visando a contribuir para o desenvolvimento pautado pela melhoria das condições de vida e a formação de uma consciência crítica. Objetiva, portanto, possibilitar os fundamentos para a formação de profissionais nas diferentes áreas de conhecimento, propiciando-lhes elementos para a formação de uma capacidade crítica e condições para contribuir com o desenvolvimento socioeconômico e cultural. Assim, busca articular-se, de forma efetiva, com o sistema de ensino básico, almejando, continuamente e de maneira recíproca, a qualidade do ensino (PDI 20152019).

\section{Os impactos das novas Diretrizes Curriculares Nacionais (DCN) para o Curso de Pedagogia}

Em 2019, o Conselho Nacional de Educação define novas Diretrizes Curriculares Nacionais para a Formação Inicial da Educação Básica e institui a Base Nacional Comum para a Formação Inicial de Professores para a Educação Básica (BNC - Formação). A proposta revoga a Resolução $\mathrm{CNE} / \mathrm{CP} \mathrm{n}^{\circ}$ 2/ 2015, que legisla sobre a formação de professores. Centros e departamentos de Educação de diversas universidades públicas do Brasil se posicionaram contrários à aprovação desse documento. 
Na mesma direção, vários autores como Dourado (2019), Freitas (2019), Evangelista (2019) e as entidades representativas dos educadores, tais como a Associação pela Formação dos Profissionais da Educação (Anfope), a Associação Nacional de Pósgraduação e Pesquisa em Educação (ANPEd), a Associação Brasileira de Currículo (ABdC), a Associação Nacional de Política e Administração da Educação (Anpae) e a Confederação Nacional dos Trabalhadores da Educação (CNTE), manifestaram-se contra a implementação da Resolução, alegando que a formação docente não pode ficar restrita à aquisição de competências, voltada à preparação para a implantação da Base Nacional Comum Curricular (BNCC). Além disso, afirmam que o processo foi encaminhado e aprovado apressadamente e sem discussão mais aprofundada com a área acadêmica, sendo uma matéria tão importante e com alto impacto para a educação básica e superior no país.

De acordo com a Anfope (2019), a Resolução acentua a mercantilização da educação e não tem preocupação com a qualidade, favorecendo a formação a distância em instituições que visam apenas ao lucro, sem mínimos padrões de qualidade, e que, hoje, são responsáveis, majoritariamente, pela formação dos professores que atuam na educação básica, impactando negativamente a qualidade do ensino. A Anfope enfatiza, ainda, que a proposta aprovada provocará a ampliação e o aprofundamento dos processos de desprofissionalização e de precarização do trabalho docente com efeitos nocivos à qualidade da educação básica.

Tal proposição descaracteriza a formação de professores em seus princípios fundamentais, como a sólida formação teórica e interdisciplinar, unidade teoriaprática, gestão democrática e a formação inicial e continuada articulada ao compromisso social da universidade a partir do tripé indissociável ensino-pesquisa-extensão e a construção de projeto institucional de formação, como propõe a Resolução 02/2015.

Para Bazzo e Scheibe (2019), a nova Resolução:

[...] ignora a necessária e essencial de valorização do profissional da educação e a autonomia pedagógica das instituições formadoras, desconsidera os avanços do pensamento educacional brasileiro adotando concepções ultrapassadas como a pedagogia das competências e uma visão restrita e instrumental de docência, entre tantos outros equívocos apontados em diversos manifestos e documentos das entidades nacionais, assim como de pesquisadores da área da educação e da formação. A alegação de necessidade de adequação dos currículos dos cursos de formação de professores à Base Nacional Comum Curricular da Educação Básica (BNCC) não é argumento ou justificativa suficiente para a alteração da Resolução 02/2015. 
Outro argumento é o de que a nova Resolução privilegia o diálogo com as instituições e fundações privadas, ignorando a ampla produção científica sobre a formação de professores e as reivindicações da comunidade acadêmica e das entidades nacionais do campo educacional.

Reconhece-se, assim, a Resolução CNE n 02/2015 como materialização de uma concepção formativa da docência que articula indissociavelmente uma política de valorização profissional dos professores, que vincula formação, carreira e condições de trabalho às demandas formativas da escola básica (AGUIAR; DOURADO 2019).

Observa-se que a nova Resolução mantém as 3.200 horas. Todavia, estabelece que esse cômputo de horas precisa estar organizado em três grupos. O Grupo I, com 800 horas, que precisam ser efetivadas desde o início no $1^{\circ}$ ano do curso. Nesse grupo, devem ser trabalhados aspectos referentes à base comum, que compreende os conhecimentos científicos, educacionais e pedagógicos e fundamentam a educação e suas articulações com os sistemas, as escolas e as práticas educacionais.

O Grupo II, com 1.600 horas, que devem ser cumpridas a partir do segundo ano do curso até o quarto ano. Nessa etapa formativa, deve ser trabalhada a aprendizagem dos conteúdos específicos das áreas, bem como componentes, unidades temáticas e objetos de conhecimento da BNCC e o domínio pedagógico desses conteúdos.

E, por fim, o Grupo III, com 800 horas, que devem ser desenvolvidas desde o primeiro ano do curso e que configuram a prática pedagógica no currículo. Esse quantitativo de horas práticas deve ser distribuído em 400 horas para o estágio supervisionado, em situação real de trabalho na escola e 400 horas para a prática dos componentes curriculares dos Grupos I e II, distribuídas ao longo do curso, desde o início.

Ao estabelecer a forma como a carga horária deve ser distribuída, não apenas em termos de horas, mas, também, em conteúdos e anos do currículo, a nova Resolução acaba por padronizar e engessar os cursos de formação de professores. A organização descrita em detalhes limita a autonomia dos cursos no que diz respeito à organização curricular. Além disso, as atividades complementares, contempladas no PPC como componente curricular dos cursos desde 2002, desaparecem das atuais DCN.

A nova proposta ainda aponta mudanças significativas para a formação de professores da Educação Infantil, Anos Iniciais do Ensino Fundamental e Gestão Educacional. A formação desses profissionais tem sido realizada historicamente nos cursos de Pedagogia, que possui diretrizes curriculares próprias (Resolução CNE/CP n. 
1/2006), as quais estabelecem que não deve haver habilitações para a formação do pedagogo, que possui a docência como base de sua formação.

No entanto, a Resolução CNE/CP n. 2/2019, no capítulo que trata dos Cursos de Licenciatura, não menciona os cursos de Pedagogia e faz referência ao "curso de formação de professores multidisciplinares da Educação Infantil" e ao "curso de formação de professores multidisciplinares dos anos iniciais do Ensino Fundamental". Até a aprovação do referido documento, esses termos não eram utilizados para se referir à formação desses docentes.

No que se refere à Gestão Educacional, a Resolução preconiza que essa formação deve ocorrer nos cursos de Pedagogia, com aprofundamento de estudos nas áreas de gestão, de 400 horas, ou seja, os cursos de Pedagogia deverão ter a carga horária mínima de 3.600 horas, estabelecendo que, para o exercício profissional das funções relativas a essas áreas, a experiência docente é pré-requisito.

O documento desconsidera o esforço empreendido pelos cursos de licenciatura do país, como é caso do curso de Pedagogia da Ufac (sede), que buscou reformular seu PPC em um rico processo de discussão coletiva e que não teve tempo de implementá-lo. Essa é uma realidade de grande parte dos cursos em âmbito nacional, vem sendo um desafio enfrentado por educadores do país inteiro. É importante enfatizar que o prazo para a atualização dos currículos para atender à Resolução CNE/CP n. 2/2015 ainda não havia se extinguido e o curso não teve sequer tempo para realizar uma avaliação acerca do impacto das mudanças, de modo a apontar os avanços e as lacunas verificadas quando de sua implementação. A imposição dessas diretrizes padronizadas e pautadas em modelos de currículo mínimo desconsideram os processos que estavam sendo construídos nas instituições de ensino superior do país.

\section{Considerações finais}

Este estudo buscou mostrar um contexto histórico e legal cheio de tensões, controvérsias e resistências em relação ao curso de Pedagogia no Brasil. O curso completa 50 anos de existência na Ufac, vem acompanhando as determinações legais em âmbito nacional e contribuindo incessantemente com a formação de professores no contexto acreano, com uma história construída e consolidada na instituição.

Atualmente, encontra-se em processo de reformulação de seu Projeto Político Pedagógico e vive um impasse no que se refere à implementação da Resolução CNE/CP 
n. 2/2019, que desconsidera todo o movimento de reformulação curricular realizado até então. Reconhece-se a existência de um descompasso entre os propositores das políticas e as instituições de ensino superior, pois, ao definir novas Diretrizes Curriculares Nacionais para a Formação de Professores sem discutir com a sociedade, especialmente a acadêmica, o atual governo nega as experiências, os estudos e pesquisas produzidos pelos educadores do campo da formação de professores.

$\mathrm{O}$ documento que, antes, atendia às Diretrizes Nacionais encontrava-se em consonância com as peculiaridades locais e com a trajetória institucional e consolidava a identidade da Universidade Federal do Acre e do curso de Pedagogia no que diz respeito à formação de professores. O Projeto do curso, neste momento, fica subsumido à nova legislação, que parece desconsiderar não apenas o processo de construção coletiva empreendido, mas, também, qualquer história institucional anterior no campo da formação docente.

A posição assumida, aqui, é a de continuidade da luta e de resistência às Diretrizes, reafirmando a importância de uma Base Comum Nacional que incorpore os princípios de uma formação unificada para os professores, que considere a diversidade brasileira e as múltiplas experiências pedagógicas, pois nenhuma proposta obterá sucesso se os professores não participarem de sua elaboração e não obtiverem maior autonomia no seu trabalho individual e coletivo.

\section{Referências}

ACRE. Lei 318 de 03 de março de 1970 que autoriza o Poder Executivo instituir da Fundação Centro Universitário do Acre e dá outras providências. Diário Oficial. Rio Branco-AC, 13 de março de 1970.

AGUIAR, Márcia Ângela da S; DOURADO, Luiz Fernandes. BNCC e formação de professores: concepções, tensões, atores e estratégias. Retratos da Escola, Brasília, CNTE, v.13, n. 25, p. 33-37, jan./mai. de 2019.

ANFOPE. A ANFOPE se posiciona em defesa da Resolução 02/215 e pede arquivamento do parecer que propõe a sua alteração, [página online], 2019. Disponível em: http://www.anfope.org.br/anfope-seposiciona-em-defesa-da-resolucao-02-215-e-pedearquivamento-do-parecer-que-propoe-a-sua-alteracao/. Acessado em: 03/10/2020.

ANFOPE. A Anfope repudia a aprovação pelo CNE da Resolução que define as novas Diretrizes Curriculares para Formação Inicial de Professores da Educação Básica e Institui a Base Nacional Comum para a Formação Inicial de Professores da Educação Básica (BNC-Formação). [página online], 2019b. Disponível em: 
http://www.anfope.org.br/anfope-repudia-a-aprovacao-pelo-cne-da-resolucaoquedefine-as-novas-diretrizes-curriculares-para-formacao-inicial-de-professores-daeducacao-basica-einstitui-a-base-nacional-comum-para-a-formacao-in/. Acessado em 03/10/2020.

ANFOPE; et al. Contra a descaracterização da Formação de Professores. Nota das entidades nacionais em defesa da Re. solução 02 /2015. [página online], 2019. Acessado em: 03/10/2020.

BAZZO, Vera; SCHEIBE, Leda. De volta para o futuro. Retrocessos na atual política de formação de professores. Retratos da Escola, Brasília, v. 13, n. 27, p. 669-84, set./dez. 2019. Disponível em: http://retratosdaescola.emnuvens.com.br. Acesso em: 3 jun. 2021.

BRASIL. Decreto-lei n. 1190, de 4 de abril de 1939. Dá organização à Faculdade Nacional de Filosofia. Diário Oficial da União. Brasília, 1939.

BRASIL. Lei n. 4.024, de 20 de dezembro 1961. Fixa as Diretrizes e Bases da Educação Nacional. Diário Oficial da União. Brasília, 1961

BRASIL. Conselho Federal de Educação. Parecer n. 251/62. Currículo mínimo e duração para o curso de Pedagogia. Documenta, n.11, p.59-65, jan./fev. 1963.

BRASIL. Lei $\mathrm{n}^{\circ} 5.540$, de 28 de novembro de 1968. Fixa normas de organização e funcionamento do ensino superior e sua articulação com a escola média, e dá outras providências. Diário Oficial da União. Brasília, 1968.

BRASIL. Conselho Federal de Educação. Parecer n. 252/69. Estudos pedagógicos superiores, mínimos de conteúdo para o curso de graduação em Pedagogia. Documento, n.100, p.101- 117, abr.1969.

BRASIL. Lei n ${ }^{\circ}$ 9.394/96, de 20 de dezembro de 1996. Estabelece as Diretrizes e Bases da Educação Nacional. Brasília, 1996.

BRASIL. Decreto n. 3.276, de 6 de dezembro de 1999. Dispõem sobre a formação em nível superior de professores para atuar na educação básica, e dá outras providencias. Diário Oficial da União. Brasília, 1999.

BRASIL. Conselho Nacional de Educação. Resolução n. 1, de 15 de maio de 2006. Institui Diretrizes Curriculares Nacionais para o Curso de Graduação em Pedagogia, licenciatura. Diário Oficial da União. Brasília, 2006.

BRASIL. Resolução CNE/CP $n^{o} 2$, de $1^{o}$ de julho de 2015. Define as Diretrizes Curriculares Nacionais para a formação inicial em nível superior (cursos de licenciatura, cursos de formação pedagógica para graduados e cursos de segunda licenciatura) e para a formação continuada. Brasília, 2015.

BRASIL. Resolução CNE/CP $n^{\circ} 1$, de 9 de agosto de 2017. Altera o Art. 22 da Resolução $\mathrm{CNE} / \mathrm{CP} \mathrm{n}^{\circ} 2$, de $1^{\circ}$ de 2015, que define as Diretrizes Curriculares Nacionais para a formação inicial em nível superior (cursos de licenciatura, cursos de formação pedagógica 
O curso de Pedagogia da UFAC: 50 anos de enfrentamento e resistência na defesa da formação de professores

para graduados e cursos de segunda licenciatura) e para a formação continuada. Brasília, 2017.

BRASIL. Resolução CNE/CP $n^{o}$ 3, de 3 de outubro de 2018. Altera o Art. 22 da Resolução CNE/CP n ${ }^{\circ}$, de $1^{\circ}$ de 2015, que define as Diretrizes Curriculares Nacionais para a formação inicial em nível. Brasília, 2018.

BRASIL. Resolução $C N E / C P n^{o} 1$, de 2 de julho de 2019. Altera o Art. 22 da Resolução $\mathrm{CNE} / \mathrm{CP} \mathrm{n}^{\circ} 2$, de $1^{\circ}$ de julho de 2015, que define as Diretrizes Curriculares Nacionais para a formação inicial em nível superior. Brasília, 2019.

BRASIL. Resolução $C N E / C P n^{\circ}$ 2, de 20 de dezembro de 2019. Define as Diretrizes Curriculares Nacionais para a Formação Inicial de Professores para a Educação Básica e institui a Base Nacional Comum para a Formação Inicial de Professores da Educação Básica (BNC-Formação). Brasília, 2019.

CARVALHO, Mark Clark Assen. Professores para as Séries Iniciais: O Dilema Da Eterna Transitoriedade. Editora: Universidade Federal Do Acre. Ufac, 2004.

CANDAU, Vera Maria Ferrão. Reformas educacionais hoje na América Latina. In: MOREIRA, A. F. B. Currículo políticas e práticas. 13. ed. Campinas: Papirus, 2013.

CEE - Conselho Estadual de Educação. Decreto Estadual 68.657, de 29 de abril de 1971, que autoriza o funcionamento do curso de Pedagogia do Centro Universitário do Acre. Rio Branco-AC, 1970.

GOODSON, Ivor F. Currículo: Teoria e História. Petrópolis: Vozes, 1995.

GOODSON, Ivor. A construção social do currículo. Lisboa: Educa, 1997.

LIMA, Elizabeth Miranda de. De Aprendiz a mestre: trajetórias de construção do trabalho docente e a identidade profissional. Tese de doutoramento apresentada à Pontifícia Universidade Católica de São Paulo, 2002.

LOPES, A. C. Apostando na produção contextual do currículo. IN: AGUIAR, Márcia Ângela da S. e DOURADO, Luiz Fernandes (orgs.) A BNCC na contramão do PNE 2014-2024: avaliação e perspectivas. Recife: ANPAE, 2018. [Livro Eletrônico].

MACEDO, E. Base nacional curricular comum: a falsa oposição entre conhecimento para fazer algo e conhecimento em si. Educação em revista, Belo Horizonte, v. 32, n. 2, p. 4568, jun. 2016.

PÉREZ GÓMEZ, Angel. O pensamento prático do professor - a formação do professor como profissional reflexivo. (In) NÓVOA, António (coord.). Os professores e a sua formação. Lisboa, Portugal: Dom Quixote, 1995.

POPKEWTIZ, Thomas S. Reforma Educacional: uma política sociológica - poder e conhecimento em educação. Porto Alegre: Artes Médicas, 1997. 
UFAC. Proposta Pedagógica do Programa de Formação de Professores para Educação Infantil e Anos Iniciais do Ensino Fundamental, 2009.

UFAC. Proposta Pedagógica do Programa de Formação de Professores para Educação Infantil e Anos Iniciais do Ensino Fundamental, 2001.

UFAC. Departamento de Educação. Curso de Pedagogia. Proposta de Reformulação Curricular do Curso de Pedagogia, 1991.

*Adriana Ramos dos Santos é Doutora em Educação pela UFPR. Professora Adjunta do Centro de Educação, Letras e Artes da Ufac. Docente permanente do Mestrado profissional em ensino de Ciências e Matemática e professora colaboradora do Programa de Pósgraduação em Educação da Ufac.

E-mail: adriana.santos@ufac.br/;

ORCID: https://orcid.org/0000-0002-7402-2670

**Mark Clark Assen de Carvalho é Doutor em Educação pela PUC/SP, com estudos de estágio pós-doutoral em Educação/UFPA. Professor Titular do Centro de Educação, Letras e Artes da Ufac, Docente Permanente do Programa de Pós-Graduação em Educação da Ufac e do Doutorado em Educação da Rede Educanorte/UFPA.

E-mail: markassen@yahoo.com.br;

ORCID: https://orcid.org/0000-0003-3638-9719

***Tatiane Castro dos Santos é Doutora em Educação pela UFF. Professora Associada do Centro de Educação, Letras e Artes da Ufac. Docente permanente do Programa de PósGraduação em Educação da Ufac e do Mestrado Profissional em Letras - Profletras/Ufac.

E-mail: tatiane.santos@ufac.br;

ORCID: https://orcid.org/0000-0003-4369-2265 